\title{
Demonstration of myosin heavy chain isoforms in rat and humans: the specificity of seven available monoclonal antibodies used in immunohistochemical and immunoblotting methods
}

\author{
V. Smerdu, ${ }^{1}$ T. Soukup ${ }^{2}$ \\ ${ }^{1}$ Institute of Anatomy, Medical Faculty, University in Ljubljana, Slovenia; ${ }^{2}$ Institute of Physiology, Czech \\ Academy of Sciences, Prague, Czech Republic
}

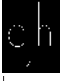

(C)2008 European Journal of Histochemistry

The aim of this paper was to present our experience with seven monoclonal antibodies, six of them were applied in immunohistochemistry and immunoblotting of MyHC isoforms in rats and humans, one of them, $6 \mathrm{H} 1$ (Lucas et al., 2000), was tested in human muscle sections only. The four antibodies specific to rat MyHC isoforms, BA-D5, SC-71, BF35, BF-F3 (Schiaffino et al., 1989) reacted as declared both on muscle sections and immunoblots of rat except SC-71 antibody, which stained MyHC-2a and $-2 x$ bands in blots. One of the two commercially available antibodies, A4.74 antibody, reliably marked type $2 a$ fibres of rat, but in blots it weakly stained MyHC-2a and $-2 x$ isoforms when used undiluted. The other one, F113.15F4, stained type $2 a$ and $2 x$ fibres and corresponding MyHC bands in blots. Therefore, using this antibody rat MyHC-2x can be additionally confirmed, which can be otherwise demonstrated only on the principle of exclusion with BF-35. Using the same set of antibodies human fast MyHC isoforms can be revealed less clearly. Namely, SC-71 and A4.74 antibodies intensively stained histochemical type $2 \mathrm{a}$, predominantly expressing $2 \mathrm{a}$ MyHC transcripts and moderately type $2 x$ fibres, expressing mostly $2 x$ MyHC transcripts, in blots the antibodies recognized both fast isoforms. The $6 \mathrm{H} 1$ antibody was the only one that selectively labelled type $2 x$ fibres, whereas BF-35 left unstained only a variable proportion of histochemical type $2 x$ fibres and MyHC-2x in blots. F113.15F4 did not distinguish between human fast fibre types and corresponding MyHC isoforms in blots. The negative results obtained with BF-F3 in muscle sections and in blots are in agreement with the absence of MyHC-2b in human skeletal muscles. Our results imply that the reactivity of antibodies specific to distinct MyHC isoforms should be carefully evaluated not only among various species but with the two different techniques used as well.

Key words: myosin heavy chains, immunohistochemistry, monoclonal antibodies, electrophoresis, immunoblotting.

Correspondence: Vika Smerdu,

Institute of Anatomy Medical Faculty, University of Ljubljana Korytkova, 21000 Ljubljana, Slovenia

Tel.: +386.15437306.

Fax:+386.154373 01

E-mail: vika.smerdu@mf.uni-lj.si

Paper accepted on July 15, 2008

European Journal of Histochemistry

2008; vol. 52 issue 3 (July-September): 179-190
$\mathrm{M}$ ammalian muscle fibres differ in their contractile properties, which are dependent on myosin heavy chains (MyHC), the main protein involved in muscle contraction. For years, the reaction for myofibrillar ATPase (mATPase), the enzyme related to $\mathrm{MyHC}$, was the routinely used method for muscle fibre classification. According to it, slow or type 1 and two fast fibre types, $2 a$ and $2 b$, could be identified. Beside these three major fibre types, type 2c fibres could be distinguished as the intermediate ones between type 1 and type $2 \mathrm{a}$ (Soukup et al., 1979).

It is known that different $\mathrm{MyHC}$ isoforms, each encoded by specific MyHC gene, determine fibre type characteristics. Up to now eight MyHC genes are well defined in rat and in human skeletal muscles: $\beta$-cardiac or $\beta$-slow (MyHC-1), $\alpha$-cardiac, $2 \mathrm{a}$, $2 \mathrm{x}, 2 \mathrm{~b}$, embryonic, perinatal and extraocular (Yoon et al., 1992; Schiaffino and Reggiani, 1996; Weiss et al., 1999a and b). The two cardiac genes are located on chromosome 14 in rats and humans (Leinwand et al., 1983; Mahdavi et al., 1984), whereas the remaining six MyHC genes are clustered on chromosome 10 in rat (Remmers et al., 1992) and 17 in humans (Yoon et al., 1992).

In slow-twitch or type 1 fibres of mature skeletal muscles MyHC-slow or $\beta$-cardiac gene is expressed in rat and humans. In fast-twitch fibres of rat MyHC-2a, $-2 x$ and $-2 b$ genes are expressed, defining type $2 \mathrm{a}, 2 \mathrm{x}$ and $2 \mathrm{~b}$ fibres respectively, expressing corresponding MyHC isoforms (De Nardi et al., 1993). On the contrary, in humans most of studies imply that only MyHC-2a and $-2 x$ genes and corresponding isoforms are respectively expressed in histochemically classified type $2 \mathrm{a}$ and $2 \mathrm{~b}$ fibres, henceforth the latter were labelled as $2 x$ (Smerdu et al., 1994; Ennion et al., 1995; Smerdu and Eržen, 2001). Though mRNA transcripts of MyHC-2b gene were revealed in certain skeletal muscles, MyHC-2b isoform has not been confirmed so far in humans (Horton et al., 2001). 
Skeletal muscles possess the ability to adapt to changed functional demands by fibre type transitions. Thus, the fibre type composition of skeletal muscles is often the interest of many scientists working on field of muscle research. The availability of monoclonal antibodies specific to different $\mathrm{MyHC}$ isoforms enabled the demonstration of $\mathrm{MyHC}$ isoforms within muscle fibres. One of the most widely used set of antibodies specific to different MyHC isoforms of rat, which enables the demonstration of all four major fibre types in this species, was prepared by Schiaffino and co-workers (1989). These antibodies were applied in human skeletal muscles as well, but according to our experience the distinction of the two fast fibre types has not always been possible and the reported results were often not in agreement (Andersen and Schiaffino, 1997; Smerdu and Eržen, 2001; Horton et al., 2001). However, there are other antibodies, some of them commercially available, whose specificity had been evaluated in different species by other scientists. In this study two commercially available anti-fast MyHC antibodies were tested for their ability to distinguish human fast MyHC isoforms. Additionally, $6 \mathrm{HI}$ antibody, specific to MyHC-2x of various species (Lucas et al., 2000) was used, but only in human muscle sections.

MyHC isoforms can also be distinguished by different migration speed through polyacrylamide gels during electrophoresis. Using western-blot technique (immunoblotting), the separated MyHC bands can be blotted to nitrocellulose membrane and subsequently revealed with corresponding monoclonal antibodies. Since the muscle tissue is disrupted in order to prepare sample homogenates, the proteins may be denatured or unfolded and consequently the epitope of an antibody can be changed, incomplete or even lost. Therefore, the specificity of each antibody should be evaluated separately on muscle tissue sections and western-blots.

In this paper, we report about our experience with the set of seven antibodies, four of them specific to MyHC isoforms of rat (Schiaffino et al., 1989) and three of them specific to fast MyHC isoforms of various species, when applied on skeletal muscle sections and on immuno-blots of MyHC isoforms in rat and humans. Since many studies of skeletal muscles include the demonstration of MyHC isoforms using specific antibodies, we believe that our experience may be valuable to other scientists working on the muscle research.

\section{Materials and Methods}

\section{Muscle samples}

Extensor digitorum longus, soleus and diaphragm muscles of rat were analysed. The animals (inbred female Lewis rats) were obtained from the authorized laboratory of the rat-breeding unit of the Institute of Physiology of the Academy of Sciences, Prague, Czech Republic (Accreditation number 1020/491/A/00). The maintenance and handling of the experimental animals followed the EU Council Directive (86/609EEC) and the investigation was approved by the Expert Committee of the Institute of Physiology of the Academy of Sciences, Prague, Czech Republic. The rat muscle samples were obtained from six adult, 4-8 month-old animals during Nembutal (sodium pentobarbital, $40 \mathrm{mg} / \mathrm{kg}$ ) anaesthesia, after which the animals were euthanized using Nembutal overdose.

Two human lower limb muscles, biceps femoris (knee flexor) and vastus lateralis (knee extensor) were analysed in this study. The samples were excised at autopsy (within 12 hours after death) from two presumably healthy male subjects ( 37 and 47 years old), who suffered sudden death. The National Medical Ethics Committee of the Republic of Slovenia approved the human muscle sampling.

The muscle samples were immediately frozen in liquid nitrogen and stored at $-80^{\circ} \mathrm{C}$ until they were processed for mATPase histochemistry and immunohistochemistry or sodium dodecyl sulphatepolyacrylamide gel electrophoresis (SDS-PAGE) and immunoblotting.

\section{Antibodies}

To identify MyHC isoforms in muscle fibres and in immuno-blots seven monoclonal antibodies specific to MyHC isoforms of different species were used (Table 1). Four of the antibodies, BA-D5, SC$71, \mathrm{BF}-35$ and BF-F3, were specific to rat MyHC isoforms (Schiaffino et al., 1989). These antibodies (supernatants) were produced in the local laboratory from corresponding cell lines provided from Deutsche Sammlung von Mikroorganismen und Zellkulturen (DSMZ, Braunschweig, Germany). Two commercially available antibodies, A4.74, according to the manufacturer (Alexis Biochemicals) specific to MyHC-2a of human, mouse, rat and rabbit and F113.15F4, specific to MyHC-2a and $-2 b$ of various species, were used as well. Additionally, for the first time we tested 
Table 1. Specificity of antibodies used in this study to rat $(1,2 c, 2 a, 2 x, 2 b)$ and human $(1,2 c, 2 a$ and $2 x)$ fibre types applied in immunohistochemistry (IH) and to corresponding MyHC isoforms in immunoblotting (IB). The working dilutions of antibodies are listed in brackets.

\begin{tabular}{|c|c|c|c|c|}
\hline \multirow[b]{2}{*}{ antibody } & \multicolumn{2}{|c|}{ rat } & \multicolumn{2}{|c|}{ human } \\
\hline & $\begin{array}{c}\text { fibre type (IH) } \\
\text { (dilution) }\end{array}$ & $\begin{array}{c}\text { MyHC (IB) } \\
\text { (dilution) }\end{array}$ & $\begin{array}{c}\text { fibre type (IH) } \\
\text { (dilution) }\end{array}$ & $\begin{array}{c}\text { MyHC (IB) } \\
\text { (dilution) }\end{array}$ \\
\hline BA-D5 & $\begin{array}{c}1,2 c \\
(1: 500-1000)\end{array}$ & $\begin{array}{c}1 \\
(1: 500)\end{array}$ & $\begin{array}{c}1,2 c \\
(1: 500-1000)\end{array}$ & $\begin{array}{c}1 \\
(1: 500)\end{array}$ \\
\hline SC-71 & $\begin{array}{c}2 c, 2 a \\
(1: 200-500)\end{array}$ & $\begin{array}{c}2 a, 2 x \\
(1: 500)\end{array}$ & $\begin{array}{c}2 c, 2 a, 2 \times 1 \\
(1: 200-1000)\end{array}$ & $\begin{array}{c}2 a, 2 x \\
(1: 500)\end{array}$ \\
\hline A4.74 & $\begin{array}{l}2 c, 2 a \\
(1: 30)\end{array}$ & $\begin{array}{c}2 a, 2 x \\
\text { (UD) }\end{array}$ & $\begin{array}{c}2 c, 2 a, 2 x^{1} \\
(1: 30)\end{array}$ & $\begin{array}{l}2 a, 2 x^{3} \\
(1: 50)\end{array}$ \\
\hline BF-35 & $\begin{array}{c}1,2 c, 2 a, 2 b \\
\text { (UD) }\end{array}$ & $\begin{array}{c}1,2 a, 2 b \\
\text { (UD) }\end{array}$ & $\begin{array}{c}1,2 c, 2 a, 2 x^{2} \\
\text { (UD) }\end{array}$ & $\begin{array}{l}1,2 a \\
\text { (UD) }\end{array}$ \\
\hline BF-F3 & $\begin{array}{c}2 b \\
(U D-20)\end{array}$ & $\begin{array}{c}2 b \\
(1: 30)\end{array}$ & $\begin{array}{c}- \\
(1: 30)\end{array}$ & $\begin{array}{c}- \\
(1: 30)\end{array}$ \\
\hline F113.15F4 & $\begin{array}{c}2 c, 2 a, 2 x \\
(1: 30)\end{array}$ & $\begin{array}{c}2 a, 2 x \\
(1: 200)\end{array}$ & $\begin{array}{c}2 c, 2 a, 2 x \\
(1: 30)\end{array}$ & $\begin{array}{c}2 a, 2 x \\
(1: 200)\end{array}$ \\
\hline $6 \mathrm{H} 1$ & $*$ & $*$ & $\begin{array}{c}2 x \\
(1: 500)\end{array}$ & $*$ \\
\hline
\end{tabular}

${ }^{12 a}$ intensively stained, $2 \mathrm{c}$ and $2 \mathrm{x}$ moderately; ${ }^{2}$ human type $2 \mathrm{x}$ fibres may be stained and unstained; ${ }^{3}$ staining of MyHC-2x remain to be verified; UD, undiluted; * not tested in this study.

recently obtained monoclonal antibody $6 \mathrm{HI}$, specific to MyHC-2x of various species (Lucas et al., 2000), but only on human skeletal muscle sections. The corresponding cell line was gifted by Dr. L. Leinwand (Department of MCD Biology, University of Colorado, Boulder, USA), the supernatant was produced in the local laboratory.

\section{Immuno- and mATPase-histochemistry}

For immunohistochemical demonstration of MyHC serial muscle cryosections (10 $\mu \mathrm{m})$ were preincubated in phosphate buffered saline containing $0.5 \%$ bovine serum albumin (PBS/BSA) and rabbit serum (1:40) for 30 minutes. Subsequently, the sections applied with primary antibody and control sections with PBS/BSA were incubated in a humidified box overnight at $4^{\circ} \mathrm{C}$. The appropriate dilutions (with PBS/BSA) of antibodies were determined and are presented in Table 1 . The reactivity of monoclonal antibodies was revealed with HRP conjugated secondary antibody ( $P$ 260; Dako), diluted 1:100 in PBS/BSA with either rat (rat muscles) or rabbit (human muscles) serum (1:40) using an indirect immunoperoxidase technique (Gorza, 1990). The control sections, incubated without primary antibody were completely unstained.
To determine fibre types, serial cryosections were processed also for mATPase reaction after alkaline preincubation at $\mathrm{pH} 9.4$ and acid preincubation at pH 4.6, 4.5 and 4.3 (Padykula and Herman, 1955; Guth and Samaha, 1969).

\section{SDS-PAGE and immunoblotting}

Myosin was extracted following the procedure described by d'Albis et al. (1979) and MyHC isoforms were separated by SDS-PAGE (Talmadge and Roy, 1993) following the procedure described by Smerdu and co-workers (2005). The electrophoresis was carried out at constant voltage (70 V) for $30 \mathrm{hrs}$ at $4^{\circ} \mathrm{C}$. The separated MyHC isoforms were transferred to a nitrocellulose membrane (pore size $0.45 \mu \mathrm{m}$, Bio-Rad) for $18 \mathrm{hrs}$ at $400 \mathrm{~mA}$ and additionally for $1 \mathrm{~h}$ at $1 \mathrm{~A}\left(4^{\circ} \mathrm{C}\right)$. The transfer buffer was prepared as described by Towbin and coworkers (1979) except that methanol was omitted. After the blotting the gels were silver-stained (Blum et al., 1987) and the stained MyHC isoform bands in the gel were used as controls to the blotted and immuno-labelled MyHC bands on the nitrocellulose membrane (for more details see Smerdu et al., 2005). The appropriate dilutions of antibodies for immunoblotting were determined, they are presented in Table 1. 


\section{In situ hybridisation}

In order to obtain further details about MyHC content in human fast fibre types, serial cryosections of human biceps femoris and vastus lateralis muscles were processed for in situ hybridisation with probes, specific to mRNA transcripts of $\beta$ slow, 2a, 2x and 2b MyHC genes (Smerdu et al., 1994; Weiss et al., 1999b). The riboprobes were prepared with digoxgenin-labelled UTP according to the guidelines of the manufacturer (Roche Molecular Biochemicals). In situ hybridisation procedure was adapted from Horton et al. (2001), with the following modifications: the sections were digested with $20 \mu \mathrm{g} / \mathrm{mL}$ of proteinase $K$ for 7.5 minutes and the site of probe hybridisation was revealed with sheep anti-digoxigenin Fab-alkaline phosphatase conjugate (1:2000).

\section{Results}

\section{The specificity of anti-MyHC monoclonal antibod- ies in rats}

Using mATPase reaction only type $1,2 \mathrm{c}, 2 \mathrm{a}$ and $2 b$ fibres were revealed in rat, whereas type $2 x$ could not be distinguished by this reaction (not shown). The four antibodies, prepared by Schiaffino and co-workers (1989), reacted on muscle sections as expected, but on immuno-blots they showed some diversion. Monoclonal antibody BA-D5, specific to MyHC- 1 , intensively stained type 1 fibres and variably also type 2c fibres, known to co-express MyHC1 and -2 a isoform (Figure 1 a). In blots BA-D5 recognized MyHC-1 isoform band (Figure 4, panel $A$, second lane). Antibody SC-71, specific to MyHC-2a of rat, recognized type $2 \mathrm{a}$ and $2 \mathrm{c}$ fibres as expect-
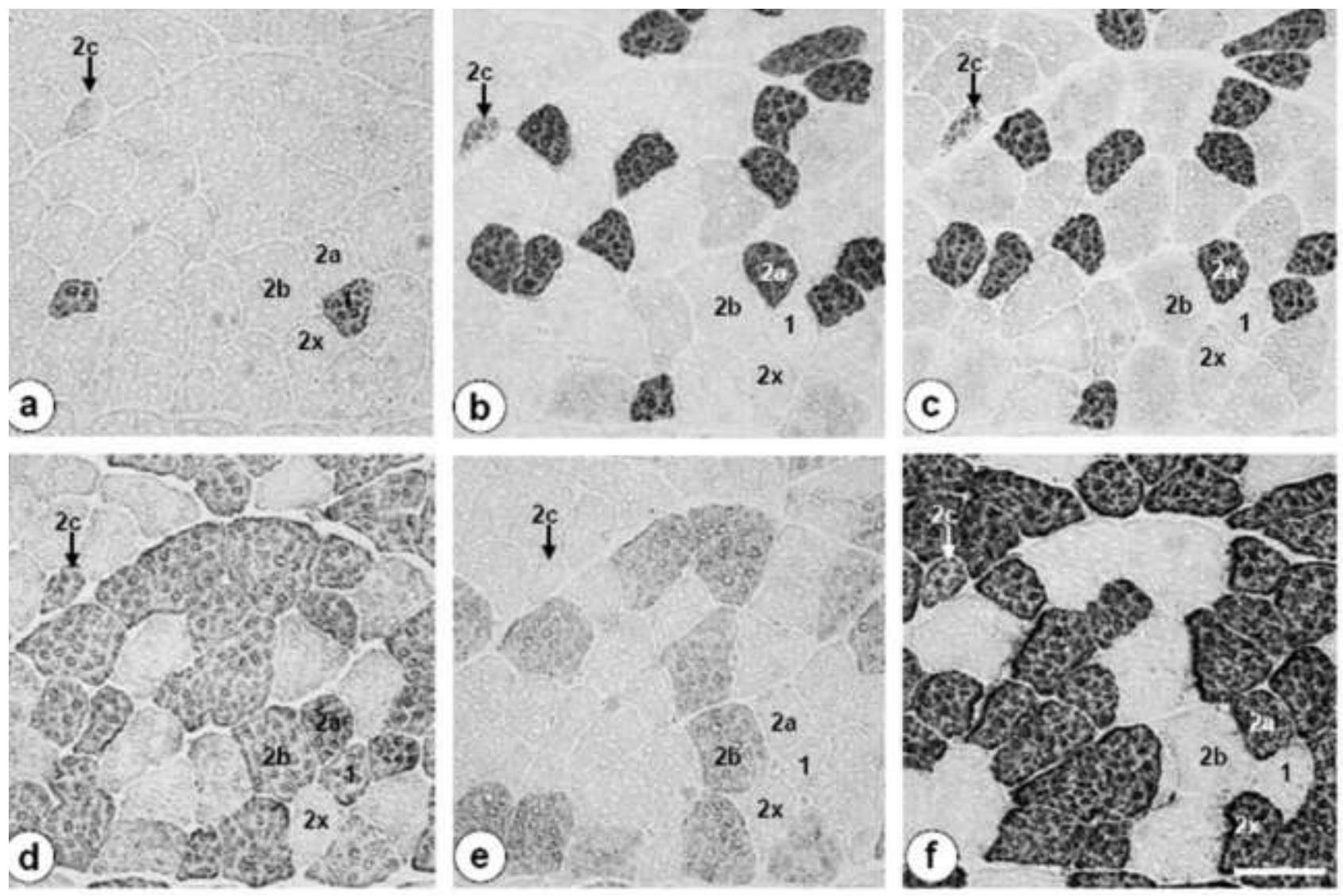

Figure 1. Reactivity of skeletal muscle fibres in rat extensor digitorum longus muscle with monoclonal antibodies directed against MyHC isoforms: a) BA-D5 (MyHC-1; 1:500), b) SC-71 (MyHC-2a; 1:500), c) A4.74 (MyHC-2a; 1: 30), d) BF-35 (recognizing all MyHC isoforms of rat except -2x; undiluted), e) BF-F3 (MyHC-2b; 1:20) and f) F113.15F4 (declared to be specific to MyHC-2a and -2b; 1:30). Fibres are labelled (1, 2c, 2a, 2x, and 2b) according to the staining characteristics with antibodies. Note that the F113.15F4 antibody stained intensively $2 a$ and $2 x$ fibres and moderately $2 c$ fibres. Scale bar is $50 \mu \mathrm{m}$. 
ed. However, type $2 \mathrm{c}$ fibres were stained with BA-D5 and SC-71 antibodies with variable intensity, obviously depending on the proportion of co-expressed isoforms (Figure $1 \mathrm{a}$ and b). On the contrary, in blots SC-71 stained MyHC-2a and MyHC-2x isoform bands with the same intensity regardless the dilution used (Figure 4, panel A, third lane). BF-35, the antibody that recognizes all MyHC isoforms of rat except $-2 x$, reacted as declared both in muscle sections and in blots, i.e. as unstained it revealed $2 x$ fibres (Figure $1 \mathrm{~d}$ ) and in blots it recognized all MyHC isoform bands except -2x (Figure 4, panel A, fifth lane). Similarly, there was no unexpected staining found with BF-F3 antibody (Figure $1 \mathrm{e}$ ), it stained type $2 \mathrm{~b}$ fibres and $\mathrm{MyHC}-2 \mathrm{~b}$ band in blots
(Figure 4, panel A, sixth lane).

Like SC-71, the A4.74 antibody recognized type 2 a fibres of rat (Figure $1 \mathrm{C}$ ), but in blots it weakly stained MyHC-2a and $-2 x$ bands if used undiluted (Figure 4, panel A, fourth lane), otherwise it did not stain any MyHC band of rat. The F113.15F4 antibody, according to the manufacturer specific to MyHC-2a and $-2 b$ of various species, stained type $2 \mathrm{c}, 2 \mathrm{a}$ and $2 \mathrm{x}$ fibres of rat (Figure $1 \mathrm{f}$ ) and corresponding two MyHC isoform bands in blots (Figure 4, panel A, seventh lane).

However, between the intensively stained and unstained fibres there was usually a certain population of fast fibres that exhibited a variable staining pattern with the applied antibodies, specific to fast
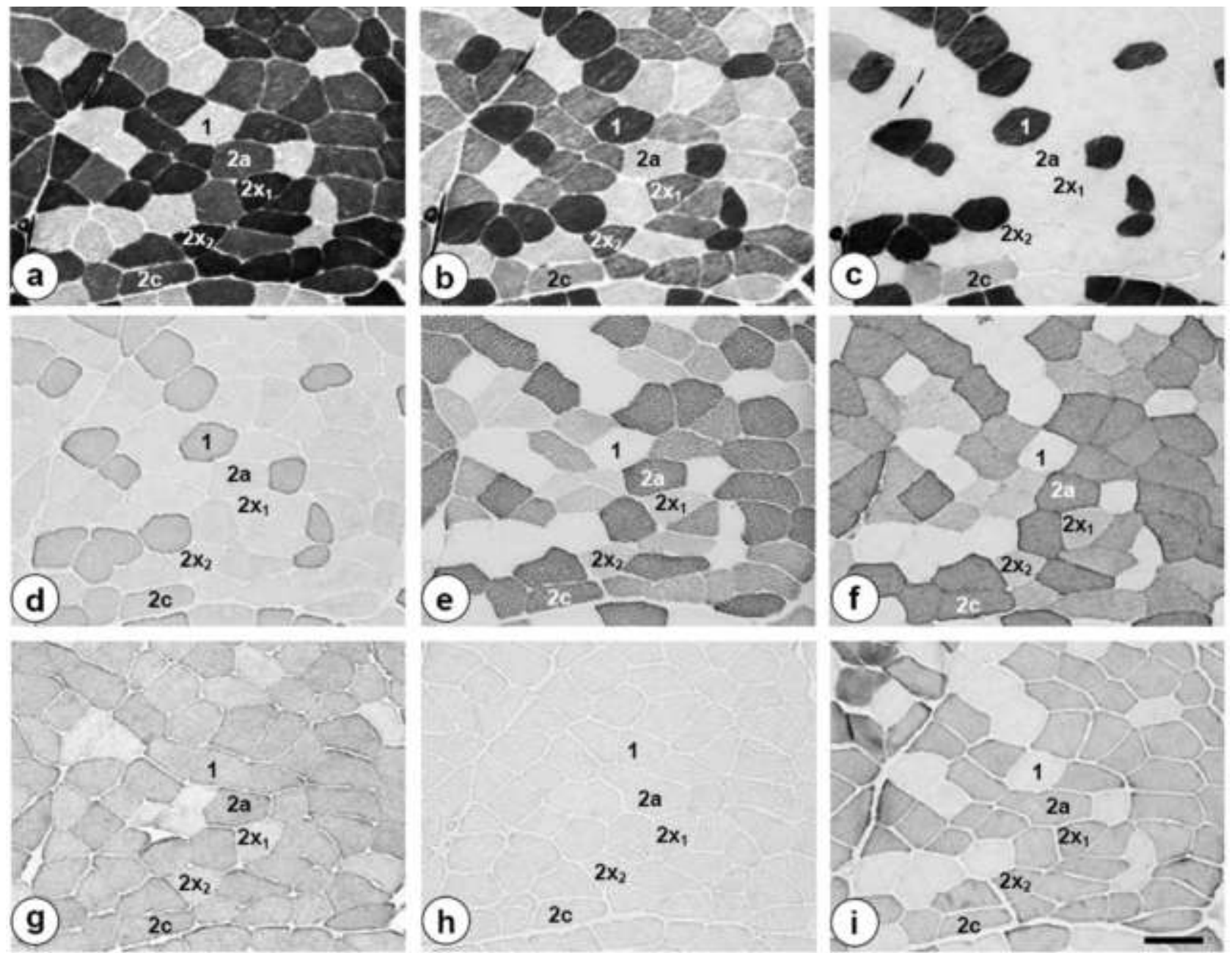

Figure 2. Reactivity of type 1, 2c, 2a and 2x fibres determined according to the mATPase reaction after preincubation at pH 9.4 (a), 4.6 (b) and 4.3 (c) with monoclonal antibodies against MyHC isoforms in human biceps femoris muscle: d) BA-D5 (MyHC-1; 1:500), e) SC-71 (MyHC-2a; 1:200), f) A4.74 (MyHC-2a; 1:30), g) BF-35 (recognizing all MyHC isoforms of rat except -2x; undiluted), h) BF-F3 (MyHC-2b; 1:20) and i) F113.15F4 (declared to be specific to MyHC-2a and -2b of various species; 1:30). Scale bar is $50 \mu \mathrm{m}$. 
MyHC isoforms, implying that they were hybrid fibres. For instance, some fibres that could be classified as unstained with BF-35 and thus considered as type $2 \mathrm{x}$, were lightly stained with SC-71, which implies that they were hybrid $2 \mathrm{ax}$ fibres, expressing mostly MyHC-2x and a small proportion of MyHC$2 \mathrm{a}$. There were also other fibres that were moderately stained with BF-35, SC-71 and A4.74 antibodies, for which we assume they were also hybrid $2 \mathrm{ax}$ fibres with more equal proportions of coexpressed isoforms. Similarly moderately stained fibres with BF-35 and BF-F3 could be classified as $2 \mathrm{xb}$. Rare fast fibres could co-express even all three fast isoforms (2axb). Since the discrimination of such hybrid fibres could be inaccurate using just bare eye, they are not labelled in Figure 1.

\section{The specificity of anti-MyHC monoclonal antibod- ies in humans}

According to the histochemical reaction for mATPase type 1,2c, 2a and 2x fibres were determined in human muscle samples (Figure $2 \mathrm{a}-\mathrm{c}$ ). Like in rat, BA-D5 stained type 1 fibres or fibres expressing $\beta$-slow MyHC transcripts (Figure 3 a) and type $2 \mathrm{c}$ fibres, however the latter ones with variable intensity (Figure $2 \mathrm{a}, \mathrm{d}$ ). In type $2 \mathrm{c}$ fibres $\beta$-slow and $2 \mathrm{a}$ MyHC transcripts were either coexpressed or one of them was exclusively expressed (not shown). In blots BA-D5 recognized MyHC-1 band (Figure 4, panel B, second lane). The antibodies SC-71 and A4.74 stained histochemical type 2a and $2 x$ human fibres (Figure $2 a-c$ ), but the latter ones less intensively (Figure $2 \mathrm{e}, \mathrm{f}$ ). Such trend of double-intensity labelling remained even when higher dilutions of both antibodies were applied (higher than 1:1000 for SC-71 and 1:200 for A4.74). The intensively labelled type $2 \mathrm{a}$ fibres predominantly expressed 2a MyHC transcripts (Figure $3 \mathrm{~b}, \mathrm{e}$, A4.74 not shown), whereas the moderately stained type 2x fibres expressed 2x MyHC transcripts (Figure $3 \mathrm{c}, \mathrm{f}, \mathrm{A} 4.74$ not shown). In the analysed samples 2b MyHC transcripts were not expressed (not shown). In blots we assume that the SC-71 and A4.74 antibodies labelled both very closely migrating $\mathrm{MyHC}-2 \mathrm{a}$ and $-2 \mathrm{x}$ bands, which were more clearly distinguished on the silver-stained gels (Figure 4, panel B, first lane) than on the membrane after the blotting (Figure 4, panel B, third and fourth lane). However like in rats, fast fibres with an intermediate staining pattern between those of type
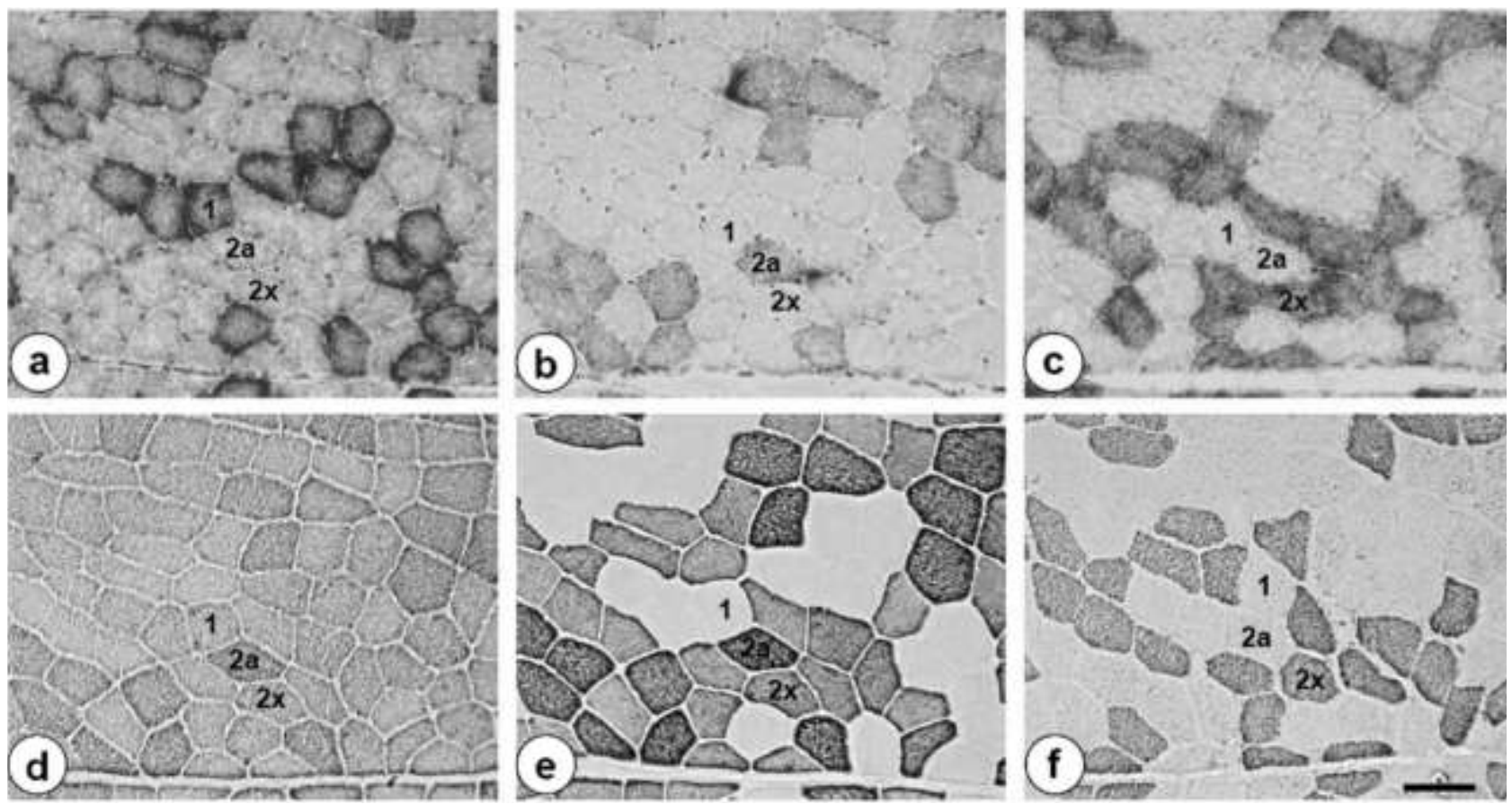

Figure 3. Expression of $\beta$ slow (a), 2a (b) and 2x (c) MyHC transcripts (mRNA) in human biceps femoris muscle revealed by digoxigeninlabelled RNA probes using in situ hybridisation technique and immunohistochemical differentiation of fibre types (1, 2a and $2 x$ ) with antibodies: d) BF-35 (all MyHC isoforms of rat except -2x; undiluted), e) SC-71 (MyHC-2a; 1:200) and f) 6H1 (MyHC-2x of various species; 1:500). Note that the intensively stained fibres with SC-71 (e), labelled as 2a, expressed 2a MyHC transcripts (b), whereas the moderately stained ones, labelled as $2 x$ and also recognized by the $6 \mathrm{H} 1$ antibody, expressed $2 x$ MyHC transcripts. Scale bar is $50 \mu m$. 
$2 \mathrm{a}$ and $2 \mathrm{x}$ fibres ( $2 \mathrm{ax}$ ) could be distinguished in sections processed for mATPase reaction and immunohistochemical staining with SC-71 and A4.74 antibodies. For the same reason as in rats the hybrid fibres are not labelled in Figure 2.

BF-35 stained fibres that were classified as type $1,2 c$, and $2 a$ according to the mATPase reaction, whereas the histochemical type $2 x$ fibres or fibres predominantly expressing $2 \mathrm{x}$ MyHC transcripts were either negative or almost unstained (labelled as $2 x_{1}$ in Figure 2) or moderately stained (labelled as $2 x_{2}$ in Figure 2 ). This antibody recognized only MyHC-1 and $-2 \mathrm{a}$ in blots (Figure 4, panel B, fifth lane). As expected, BF-F3, specific to MyHC-2b of rat, did not react with any of the human fibre types (Figure $2 \mathrm{~h}$ ) or MyHC bands at all (Figure 4, panel B, sixth lane). Antibody F113.15F4 stained both fast human fibre types (Figure $2 \mathrm{i}$ ) and both fast MyHC in blots (Figure 4, panel B, seventh lane).

The antibody $6 \mathrm{HI}$, declared to be specific to MyHC-2x of various species, labelled those fibres that were moderately stained with SC-71 (Figure 3 $\mathrm{e}, \mathrm{f}$ ) and A4.74 (not shown), corresponded to histochemical type $2 x$ fibres and predominantly expressed 2x MyHC transcripts (Figure 3c).

\section{Discussion}

In this study we found that the reactivity of antibodies specific to distinct MyHC isoforms should be carefully evaluated not only among various species but with the two different techniques used, the immunohistochemistry and immunoblotting, as well. Whereas in rat fibre types and $\mathrm{MyHC}$ isoforms in immunoblots could be quite reliably distinguished with the antibodies used, a clear identification of human fast isoforms in muscle fibres and in blots was not always possible.

In rat, using the set of antibodies specific to rat $\mathrm{MyHC}$ only the reactivity of SC-71 and A4.74 with $\mathrm{MyHC}-2 \mathrm{a}$ and-2x MyHC bands in blots was partly unexpected finding of this study. SC-71 antibody should recognize the undigested rat $\mathrm{MyHC}-2 \mathrm{a}$ according to Schiaffino and co-workers (1989). We assume that in blots in which the authors tested the specificity of this antibody, MyHC-2a and - $2 x$ isoforms co-migrated and were thus both labelled with this antibody. After the denaturation the epitopes of both antibodies must have become accessible in MyHC-2x isoform. Nevertheless, MyHC-2a and $-2 x$ bands of rat can be distinguished with BF-35 anti-

\section{A. rat}

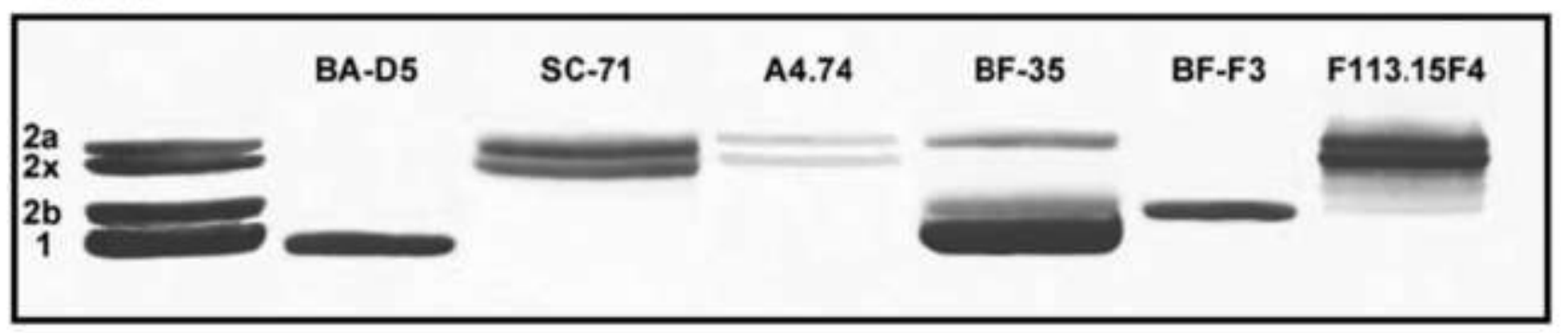

B. human

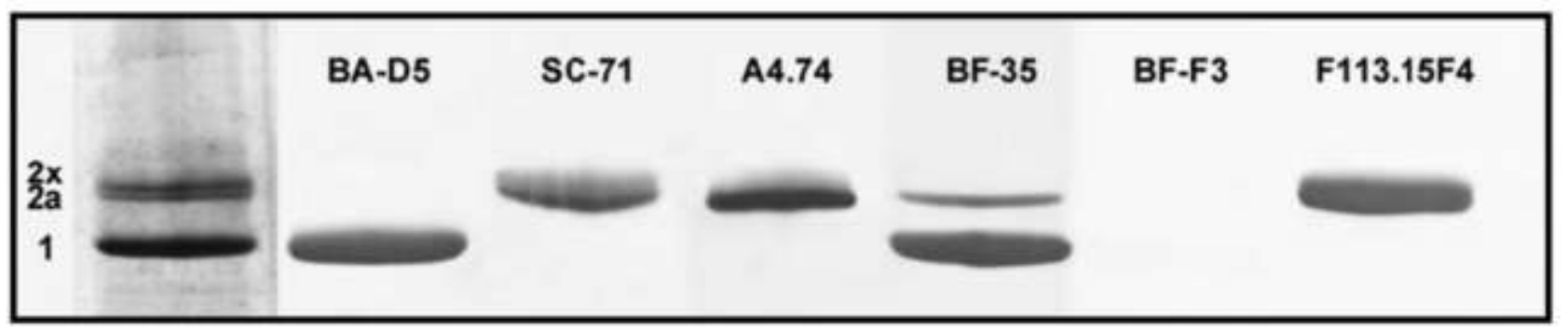

Figure 4. Identification of MyHC isoforms with immunoblotting technique in extensor digitorum longus muscle of rat (A) and human biceps femoris muscle (B). In the first lane from left in panel A MyHC isoforms (1, 2a, 2x, 2b) from mixed rat muscle sample (soleus and extensor digitorum longus) and in panel B human MyHC isoforms (1, 2a, 2x) from biceps femoris muscle, separated by SDS-PAGE technique and silver-stained, are shown. In other lanes of panel $A$ and $B$ the blots of the respective muscles were incubated with a set of monoclonal antibodies specific to MyHC isoforms: BA-D5 (MyHC-1; 1:500), SC-71 (MyHC-2a; 1: 500), A4.74 (MyHC-2a; undiluted in rat, 1: 50 in human samples), d) BF-35 (all MyHC isoforms of rat except -2x; undiluted), BF-F3 (MyHC-2b; 1:30) and F113.15F4 (declared to be specific to MyHC-2a and -2b; 1:200). 
body, that stains all MyHC except -2x. Using appropriate dilutions and supposing that the staining intensity of fibres is proportional to the proportion of the expressed MyHC isoforms, even the identification of hybrid fibres ( $2 c$ or $1 / 2 a, 2 a x, 2 a x b, 2 x b$ ) is possible with these antibodies (Soukup et al., 2002 and 2009, in press).

The F113.15F4 was found to be useful to accomplish rat fast isoforms distinction as it labelled MyHC-2a and $-2 x$ in muscle sections and in blots. Our finding is in agreement with that of Marini and co-workers (1989), who reported that a subpopulation of histochemically determined type IIB fibres of rat were unlabelled with this antibody, obviously they expressed $\mathrm{MyHC}-2 \mathrm{~b}$, whereas the labelled ones MyHC-2x as it was found later (Schiaffino et al., 1989). Therefore, using F113.15F4 in rat, MyHC$2 x$ fibres can be additionally confirmed on the principle of positive reaction and $2 b$ fibres as the negative ones. Furthermore, hybrid fibres co-expressing MyHC-2x isoform can be revealed, which is less reliable using $\mathrm{BF}-35$. The $6 \mathrm{HI}$ antibody, declared to be specific to MyHC-2x of rat as well (Lucas et al., 2000), is another promising tool for the demonstration of MyHC-2x in rat and is in the process of testing in our laboratory.

In human skeletal muscles slow MyHC could be easily distinguished from the fast ones both in muscle sections and in blots. The BA-D5 antibody reliably recognizes slow MyHC isoform in various species (Smerdu and Eržen, 2001; Štrbenc et al., 2004; Smerdu et al., 2005;. Acevedo and Rivero, 2006). Thus it seems that the BA-D5 epitope in MyHC-1 isoform is highly conserved among species, as corresponding $\beta$-slow MyHC gene is originating from the common ancestor gene (Weiss et al., 1999a and b).

On the contrary, the identification of human fast fibre types, especially the hybrid ones, and fast $\mathrm{MyHC}$ bands in blots was less clear. Unfortunately, both antibodies specific to MyHC-2a in rat, i.e. SC71 and A4.74, labelled human type $2 a$ and $2 x$ fibres as determined according to the mATPase reaction, the latter one less intensively. Though MyHC-2a and $2 x$ migrated very closely in gels, we assume that both antibodies labelled both fast isoforms in blots. The trend of such double-intensity labelling of fast fibres persisted even if higher dilutions of the antibodies were used.

The same staining pattern in human skeletal muscles as found by us has been reported by others as well (Stål et al., 1994; Andersen and Schiaffino, 1997; Monemi et al., 1999; Serrano et al., 2001). The reactivity of SC-71 with both human fast isoforms in blots as found in the present study has been also reported by Bamman and co-workers (1998), but in another study only MyHC-2a band was labelled (Serrano et al., 2001). On the contrary, it has been reported that SC-71, originating from American Type Culture Collections (ATCC), specifically labelled only human type $2 \mathrm{a}$ fibres and corresponding MyHC band in blots (Horton et al., 2001). Using SC-71 produced in the original laboratory (Schiaffino et al., 1989) and later in the local laboratory from hybridomas provided from DSMZ (Braunschweig, Germany), we have never noticed so specific staining of human type 2 a fibres. Furthermore, this antibody stained type $2 a$ and $2 x$ fibres in those mammalian species in which only these two fast fibre types exist (see Acevedo and Rivero, 2006) except of horse in which only type $2 \mathrm{a}$ fibres and $\mathrm{MyHC}-2 \mathrm{a}$ isoform band were labelled (Rivero et al., 1999; Yamano et al., 2005). But in dog, where only type $2 a$ and $2 x$ fibres were present as well, SC-71 labelled type 2 a fibres only if used highly diluted, in blots both fast isoforms were stained (Štrbenc et al., 2004; Smerdu et al., 2005).

Considering the specificity of A4.74 antibody to human MyHC-2a, the manufacturer refers to Hughes and co-workers (1993), who presented the A4.74 reactivity with MyHC-2a isoform band in blots from adult human diaphragm only and not on muscle sections. Since the MyHC-2x band (marked as IIb in the paper) was very weak in the presented SDS-PAGE separation, we assume that it could be too weak to be labelled with the antibody. Therefore we conclude that A4.74 is not specific exclusively to human MyHC-2a as declared. Even in dog both fast fibre types and corresponding $\mathrm{MyHC}$ isoforms in blots were recognized by A4.74 (Smerdu et al., 2005), but in horse like SC-71 the antibody A4.74 labelled only type 2 a fibres (Rivero et al., 1996).

The BF-35 antibody has for years remained the most frequently used antibody for demonstration of MyHC-2x, though its disadvantage that it reveals MyHC-2x as unstained. Already in our previous study, analysing a large number of fibres from 14 different human skeletal muscles, we found that this antibody, which recognized MyHC-1 and $-2 \mathrm{a}$ in human blots, is not reliable for type $2 x$ discrimination. Even with higher dilutions used BF-35 labelled about $50 \%$ of histochemical type $2 x$ fibres and 
about $60 \%$ of fibres expressing 2x MyHC transcripts as revealed by in situ hybridisation technique. Since the proportion of type $2 x$ fibres stained by BF-35 varied among different human muscles, we assumed that only pure $2 x$ fibres remained unstained (Smerdu and Eržen, 2001). The same trend was noticed in this study (see Figure 2 and 3). Nevertheless, in some muscle samples histochemical type $2 x$ fibres, which are moderately stained by $\mathrm{SC}-71$ and $\mathrm{A} 4.74$, remain unstained by BF-35. Similar results regarding the specificity of BF-35 in human skeletal muscles were reported by others as well (Bamman et al., 1998; Serrano et al., 2001). Moreover, the lack of BF-35 epitope seems to be common to MyHC-2x isoform of different mammals, as this antibody is able to reveal as unstained MyHC-2x isoform also in other mammalian species (see Acevedo and Rivero, 2006), but in opossum muscles type $2 x$ fibres were labelled by BF-35 (Sciote and Rowlerson, 1998).

The F113.15F4 antibody is not very useful for human fast fibre types differentiation as it labelled both fast isoforms in muscle sections and in blots. The same was found in other species, in which only $2 \mathrm{a}$ and $2 \mathrm{x} \mathrm{MyHC}$ isoforms exist, i.e. in dog and cattle (Štrbenc et al., 2004; Smerdu et al., 2005; Picard et al., 1998). The absence of staining with BF-F3 is in agreement with the absence of type $2 b$ fibres and corresponding $2 \mathrm{~b} \mathrm{MyHC}$ transcripts in human skeletal muscles (Smerdu et al., 1994; Ennion et al., 1995, Horton et al., 2001; this study). The same was found in equine and canine muscles, in which type $2 b$ fibres are not present as well (Rivero et al., 1996; Štrbenc et al., 2004; Smerdu et al., 2005). But like in rat, BF-F3 labelled porcine type $2 \mathrm{~b}$ fibres (Lefaucheur et al., 2002; Toniolo et al., 2004), thus this antibody obviously recognizes MyHC-2b isoform only. Therefore, the only antibody that clearly distinguished among human type $2 \mathrm{a}$ and $2 \mathrm{x}$ fibres was just recently obtained $6 \mathrm{Hl}$, which was for this report tested only on human muscle sections and it stained type $2 x$ fibres or fibres that were moderately stained with SC-71 and A4.74. The 6HI specifically recognises human MyHC-2x in blots as well (Li et al., 2004).

Considering all the above mentioned facts, a question imposes itself, why the specificity of SC-71, A4.74 and BF-35 antibodies varies among the species and why the distinction not only of human but of other large mammalian fast fibre types as well is so difficult with these antibodies. We see three possible explanations.

First, since it is known that that orthologue $\mathrm{MyHC}$ isoforms exhibit higher similarity in their amino acid sequence than paralogues, quite similar staining pattern of fast fibre types among large mammals could be expected. Thus the variable staining pattern of these antibodies among different species could be the consequence of different concentrations and sources of the antibodies, perhaps even of the inversion of their specificity and differences in immunohistochemical protocols. However, the differences in the fast MyHC isoforms proportions in fast fibres among different muscles and species should not be neglected.

Second, the double intensity labelling of fast fibres with the SC-71 and A4.74 antibodies in humans and other mammalian species could result in the fact that fast MyHC isoforms (paralogues) also exhibit quite high degree of homogeneity as they have obviously developed from a common ancestor gene (Weiss et al., $1999 \mathrm{a}$ and b). Thus fast MyHC isoforms may share the epitopes of different antibodies. In humans, the epitopes of SC-71 and A4.74 antibodies could be more abundant or perhaps more accessible in MyHC-2a isoform, as type 2 a fibres were more intensively stained. It is also possible that both antibodies have differential affinity to the epitopes on the two human fast $\mathrm{MyHC}$ isoforms. Considering the above described facts, we could assume that the SC-71 and A4.74 antibodies differentially recognize human MyHC$2 \mathrm{a}$ and $-2 \mathrm{x}$ isoform. Accordingly, the hybrid $2 \mathrm{ax}$ fibres would exhibit a continuum of staining intensities between those of type $2 a$ and $2 x$, which might be reliably evaluated with highly standardized immunohistochemical procedure and microphotometric technique (Acevedo and Rivero, 2006).

Third, if supposed that the SC-71 and A4.74 antibodies selectively recognize $\mathrm{MyHC}-2 \mathrm{a}$ in muscle fibres, the double intensity labelling of fast fibres in skeletal muscles of humans and of those species with similar staining pattern with the two antibodies, would mean that these muscles contain no pure type $2 x$ fibres. The moderately stained fast fibres would be then the hybrid 2 ax fibres. The fact, that all moderately stained fast fibres in this study, labelled with the $6 \mathrm{HI}$ antibody as well, were mostly stained with BF-35 as seen in Figure 3, also implies for the absence of pure $2 x$ fibres.

Though aware that the expression of mRNA transcripts of MyHC genes does not match com- 
pletely with the expressed MyHC isoforms (Andersen and Schiaffino, 1997; Smerdu and Eržen, 2001), but still offers additional information about MyHC status in fibres, we compared the specificity of the SC-71, A4.74, BF-35 and $6 \mathrm{HI}$ antibodies with MyHC transcript expression in fibres. The predominant expression of $2 \mathrm{x} \mathrm{MyHC}$ transcripts within moderately stained human fast fibres and their histochemical profile (type $2 x$ ) rather indicate for the existence of pure $2 x$ fibres. Namely, if a permanent population of hybrid fibres is present in human skeletal muscles, then the coexpression of both corresponding MyHC transcripts would be expected in these fibres. However, it is possible that the expression of $2 \mathrm{a}$ MyHC transcripts in the moderately stained fast fibres is so weak that it is beyond the sensitivity of the in situ hybridisation technique. Nevertheless, a high percentage of hybrid $2 \mathrm{ax}$ and quite low share or even the absence of pure $2 x$ fibres had been found in human skeletal muscles (Staron, 1991; Larsson and Moss, 1993; Harridge et al., 1996). These fibres probably allow a highly sensitive tuning of muscle contraction properties with functional demands of organism.

Therefore, a comparative analysis of $\mathrm{MyHC}$ extracts of single fibres by SDS-PAGE, immunohistochemical profile of fibres, determined with antibodies that would reliably distinguish both fast isoforms, especially MyHC-2a could provide us the final answer to the above imposed questions. Considering the differences in $\mathrm{MyHC}$ isoforms content among different muscles, several different human skeletal muscles should be analysed.

In conclusion, according to our experience the demonstration of fast MyHC isoforms with antibodies may be quite difficult due to high homogeneity of fast paralogue isoforms and probably due to common appearance of hybrid fast fibres, particularly in human skeletal muscles in which the $6 \mathrm{HI}$ antibody was found as a promising tool for the future studies. Furthermore, the reactivity of antibodies should be carefully evaluated among different species and techniques used.

\section{Acknowledgements}

We thank to Mrs. Andreja Vidmar, Mrs. Nataša Pollak, Mrs. Majda Črnak-Maasarani, Mrs. Polona Vozelj, Mr. Marko Slak and Mr. Milan Števanec for their technical assistance. The research was supported by the Public Agency of the Republic
Slovenia for Research (P3-043), Czech-Slovenian Intergovermental Grant (02-2004-05), MYORES LSH-CT-2004-511978 and by grant 304/08/0256 from the Grant Agency of the Czech Republic and by the Research project AVOZ 50110509.

\section{References}

Acevedo LM, Rivero JLL. New insights into skeletal muscle fibre types in the dog with particular focus towards hybrid myosin phenotypes. Cell Tissue Res 2006;323:283-303.

Andersen LJ, Schiaffino S. Mismatch between myosin heavy chain mRNA and protein distribution in human skeletal muscle fibres. Am J Physiol 1997;272:C1881-9.

Bamman MM, Clarke MSF, Feeback DL, Talmadge RJ, Stevence BR, Lieberman SA et al. Impact of resistance exercise during bed rest on skeletal muscle sarcopenia and myosin isoform distribution. J Appl Physiol 1998;84:157-63.

Blum M, Beier H, Gross MJ. Improved silver staining of plant proteins, RNA and DNA in polyacrylamide gels. Electrophoresis 1987;8: 93-9.

$\mathrm{d}^{\prime}$ Albis A, Pantaloni C, Brecht JJ. An electrophoretic study of native myosin isozymes and of their subunit content. Eur $\mathrm{J}$ Biochem 1979;99:261-72.

DeNardi C, Ausoni S, Moretti P, Gorza L, Velleca M, Buckingham M, et al. Type $2 x$ myosin heavy chain is coded by a muscle fiber typespecific and developmentally regulated gene. J Cell Biol 1993; 123:823-35.

Ennion S, Sant'Ana Pereira J, Sargeant AJ, Young A, Goldspink G. Characterization of human skeletal muscle fibres according to the myosin heavy chains they express. J Muscle Res Cell Motil 1995; 16:35-43.

Gorza L. Identification of a novel type 2 fiber population in mammalian skeletal muscle by combined use of histochemical myosin ATPase and anti-myosin monoclonal antibodies. J Histochem Cytochem 1990;38:257-65.

Guth L, Samaha FJ. Qualitative differences between actomyosin ATPase of slow and fast mammalian muscle. Exp Neurol 1969;25:138-52.

Harridge SDR, Bottinelli R, Canepari M, Pellegrino MA, Reggiani C, Esbjörnsson $M$ et al. Whole-muscle and single-fibre contractile properties and myosin heavy chain isoforms in humans. Pflügers Arch-Eur J Physiol 1996; 432:913-20.

Horton MJ, Brandon CA, Morris TJ, Braun TW, Yaw KM, Sciote JJ. Abundant expression of myosin heavy-chain IIB RNA in a subset of human masseter muscle fibres. Arch Oral Biol 2001;57:1039-50.

Hughes SM, Cho M, Karsch-Mizrachi I, Travis M, Silberstein L, Leinwand $L A$, et al. Three slow myosin heavy chains sequentially expressed in developing mammalian skeletal muscle. Dev Biol 1993; 158:183-99.

Larsson L, Moss RL. Maximum velocity of shortening in relation to myosin isoform composition in single fibres from human skeletal muscles. J Physiol 1993; 472:595-614.

Lefaucheur L, Ecolan P, Plantard L, Gueguen N. New insights into muscle fiber types in the pig. J Histochem Cytochem 2002;50:719-30.

Leinwand LA, Fournier RE, Nadal-Ginard B, Shows TB. Multigene family for sarcomeric myosin heavy chain in mouse and human DNA: localization on a single chromosome. Science 1983; 221:766-9.

Li ZB, Lehar M, Nakagawa H, Hoh JFY, Flint PW. Differential expression of myosin heavy chain isoforms between abductor and assuctor muscles in the human larynx. Otolaryngol Head Neck Surg 2004; 130:217-22.

Lucas CA, Kang LHD, Hoh JFY. Monospecific antibodies against the three mammalian fast limb myosin heavy chains. Biochem Biophys Res Commun 2000;272:303-8.

Mahdavi V, Chambers AP, Nadal-Ginard B. Cardiac alpha- and betamyosin heavy chain genes are organized in tandem. Proc Natl Acad Sci USA 1984;81:2626-30.

Marini J-F, Pons F, Anoal M, Leger J, Leger JJ. Anti-myosin heavy 
chain monoclonal antibodies reveal two IIB (fast) fiber subtypes. J Histochem Cytochem 1989;37: 1721-9.

Monemi M, Eriksson PO, Kadi F, Butler-Browne GS, Thornell LE. Opposite changes in myosin heavy chain composition of human masseter and biceps brachii muscles during aging. J Muscle Res Cell Motil 1999;20:351-61.

Padykula HA, Herman E. The specificity of the histochemical method for adenosine triposphate. J Histochem Cytochem 1955;3:170-83.

Picard MP, Duris MP, Jurie C. Classification of bovine muscle fibres by different histochemical techniques. Histochem J 1998;30:473-9.

Remmers EF, Goldmuntz EA, Cash JM, Crofford LJ, MisiewiczPoltorak B, Zha H, et al. Genetic map of nine polymorphic loci comprising a single linkage group on rat chromosome 10: evidence for linkage conservation with human chromosome 17 and mouse chromosome 11. Genomics 1992; 14:618-23.

Rivero JLL, Talmadge JR, Edgerton VR. Myosin heavy chain isoforms in adult equine skeletal muscle: an immunohistochemical and electrophoretic study. Anat Rec 1996;246:185-94.

Rivero JLL, Serrano AL, Barrey E, Valette JP, Jouglin M. Analysis of myosin heavy chains at the protein level in horse skeletal muscles. J Muscle Res Cell Motil 1999;20:211-21.

Sciote JJ, Rowlerson A. Skeletal fiber types and spindle distribution in limb and jaw muscles of adult and neonatal opossum, Monodelphis domestica. Anat Rec 1998;251:548-62.

Schiaffino S, Reggiani C. Molecular diversity of myofibrillar proteins: gene regulation and functional significance. Physiol Rev 1996;76:371-423.

Schiaffino S, Gorza L, Sartore S, Saggin L, Vianello M, Gundersen K, et al. Three myosin heavy chain isoforms in type 2 skeletal muscle fibres. J Muscle Res Cell Motil 1989;10:197-205.

Serrano AL, Perez M, Lucia A, Chicharro JL, Quiroz-Rothe E, Rivero JLL. Immunolabelling, histochemistry and in situ hybridisation in human skeletal muscle fibres to detect myosin heavy chain expression at the protein and mRNA level. J Anat 2001;199:329-37.

Smerdu V, Karsch-Mizrachi I, Campione M, Leinwand L, Schiaffino S. Type IIx myosin heavy chain transcripts are expressed in type IIb fibers of human skeletal muscle. Am J Physiol 1994;267:C1723-8.

Smerdu V, Eržen I. Dynamic nature of fibre-type specific expression of myosin heavy chain transcripts in 14 different human skeletal muscles. J Muscle Res Cell Motil 2001; 22:647-55.

Smerdu V, Štrbenc M, Meznarič-Petruša M, Fazarinc G. Identification of myosin heavy chain I, IIa and IIx in canine skeletal muscles by an electrophoretic and immunoblotting study. Cells Tissues Organs 2005; 180:106-16.
Soukup T, Vydra J, Černy M. Changes in ATPase and SDH reactions of the rat extrafusal and intrafusal muscle fibres after preincubations at different $\mathrm{pH}$. Histochemistry 1979;60:71-84.

Soukup T, Zachafiova G, Smerdu V. Fibre type composition of soleus and extensor digitorum longus muscles in normal female inbred Lewis rats. Acta Histochem 2002;104:399-405.

Soukup T, Smerdu V, Maláčová D, Zachařová G. Fiber type composition of unoperated rat soleus and extensor digitorum longus muscles after unilateral isotransplantation of a foreign muscle in long-term experiments. Physiol Res 2009;58:000-000, in press.

Stål $P$, Eriksson PO, Schiaffino $S$, Butler-Browne GS, Thornell LE. Differences in myosin composition between human oro-facial, masticatory and limb muscles: Enzyme-, immunohisto- and biochemical studies. J Muscle Res Cell Motil 1994;15:517-34.

Staron RS. Correlation between myofibrillar ATPase activity and myosin heavy chain composition in single human muscle fibers. Histochemistry 1991;96:21-4.

Štrbenc M, Smerdu V, Županc M, Tozon N, Fazarinc G. Pattern of myosin heavy chain isoforms in different fibre types of canine trunk and limb skeletal muscles. Cells Tissues Organs 2004;176:178-86.

Talmadge RJ, Roy RR. Electrophoretic separation of rat skeletal muscle myosin-heavy chain isoforms-rapid comunication. J Appl Physiol 1993; 75:2337-40.

Toniolo L, Patruno $M$, Maccatrozzo $L$, Pellegrino MA, Canepari $P$, Rossi R, D'Antona G, Bottinelli R, Reggiani C, Mascarello F. Fast fibres in a large animal: fibre types, contractile properties and myosin expression in pig skeletal muscles. J Exp Biol 2004; 207:1875-86.

Towbin H, Staehelin T, Gordon J. Electrophoretic transfer of proteins from polyacrylamide gels to nitrocellulose sheets: procedure and some applications. Proc Natl Acad Sci USA 1979;76:4350-4.

Weiss A, McDonough D, Wertman B, Acakpo-Satchivi L, Montgomery $\mathrm{K}$, Kucherlapati $\mathrm{R}$, et al. Organization of human and mouse skeletal myosin heavy chain gene clusters is highly conserved. Proc Natl Acad Sci USA 1999a; 96:2958-63.

Weiss A, Schiaffino S, Leinwand LA. Comparative sequence analysis of the complete human sarcomeric myosin heavy chain family: implication for functional diversity. J Mol Biol 1999b;290:61-75.

Yamano S, Eto D, Kasashima $Y$, Hiraga A, Sugiura T, Miyata H. Evaluation of developmental changes in the coexpression of myosin heavy chains and metabolic properties of equine skeletal muscle fibers. Am J Vet Res 2005;66:401-5.

Yoon SJ, Seiler SH, Kucherlapati R, Leinwand LA. Organization of the human skeletal myosin heavy chain gene cluster. Proc Natl Acad Sci USA 1992;89:12078-82. 
V. Smerdu and T. Soukup 